\author{
Claudia-Paula Heidegger \\ Jacques-André Romand \\ Miriam M. Treggiari \\ Claude Pichard
}

\section{Is it now time to promote mixed enteral and parenteral nutrition for the critically ill patient?}

Received: 8 September 2006

Accepted: 2 April 2007

Published online: 28 April 2007

(C) Springer-Verlag 2007

C.-P. Heidegger ( ) J.-A. Romand · M. M. Treggiari Geneva University Hospital, Service of Intensive Care, Rue Micheli-du-Crest 24, 1211 Geneva 14, Switzerland e-mail: claudia-paula.heidegger@hcuge.ch

Tel.: +41-22-3827460

Fax: +41-22-3827470

C. Pichard

Geneva University Hospital, Clinical Nutrition,

1211 Geneva 14, Switzerland improved intensive care outcomes. Supplemental PN combined with EN could be an effective alternative to achieve $100 \%$ of energy and protein targets at day 4 , when EN alone fails to achieve goals greater than $60 \%$ by day 3 . Whether such combined nutrition support provides additional benefit on overall outcome has to be ascertained in further studies.

Keywords Nutritional support - Critical care - Human · Practice guidelines - Standards - Enteral nutrition - Parenteral nutrition $\cdot$ Outcome $\cdot$ Combined nutrition

\section{Introduction}

For many years the major concern of physicians caring for critically ill patients was to stabilise vital signs, including haemodynamic and respiratory function, and to control infection. Nutrition was often a second priority. During the past decade, however, increasing evidence in critical care medicine suggests that optimal nutritional management of critically ill patients could positively influence clinical outcome. The rationale for nutritional support is based on the observation that critically ill patients undergo an obligatory catabolic phase. This is associated with protein breakdown to produce energy and amino acids, a metabolic condition resulting in protein-energy malnutrition and with an increased rate of complications, including infections, multiple organ failure, poor outcome and prolonged length of stay [1-7]. In ICU patients, the cumulated deficit has been associated with increased morbidity [8]. In addition, up to $50 \%$ of patients admitted to European hospitals have various degrees of malnutrition [9]. Thus, standards of care for ICU patients should include nutritional support.

Over the years, opinion on the best nutritional support administration route has evolved. This was demonstrated 
by Berger et al., who described the change in nutritional support techniques in a surgical ICU over a 10-year period [10]. A considerable change was observed, evolving from the predominant use of total parenteral nutrition (TPN) to the wide use of enteral nutrition (EN). However, when EN is systematically used in ICU patients, a protein-energy deficit is often observed. First, the full coverage of nutritional needs by $\mathrm{EN}$ is often reached only after 5-7 days. This is due to relative gastrointestinal intolerance and temporary cessation of feeding during patient care or investigations $[11,12]$. Second, EN delivery frequently differs from the amount prescribed by the physician [13, 14]. Moreover, there is still some confusion regarding the optimal timing for initiation of nutritional support. In practice, it commonly takes up to 7 days before full coverage of energy needs is achieved [15]. With these limitations in mind, in order to prevent both protein and

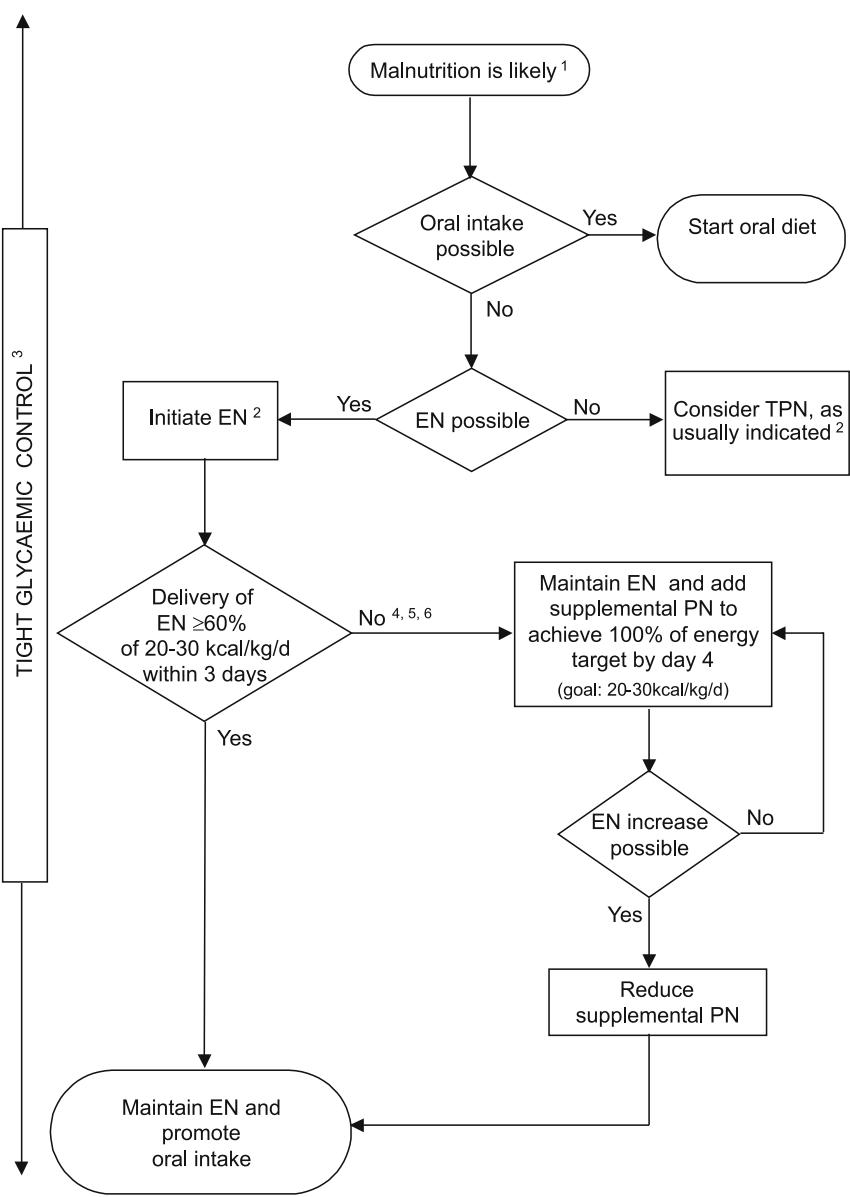

Fig. 1 Nutrition in critically ill patients: revisiting the approach to nutrition with enteral $(E N)$ and supplemental $(P N)$ support maintaining glycaemic control. Notes: 1 At admission, $30-50 \%$ of patients have pre-existing malnutrition and are at risk of developing acute malnutrition in the ICU [9]; 2 EN reduces morbidity in ICU patients [54]; 3 glycaemic control reduces morbidity and mortality [49]; 4 inadequate $\mathrm{EN}$ is frequent [12]; 5 inadequate $\mathrm{EN}$ increases morbidity and length of stay [8]; 6 early TPN reduces mortality [44] calorie deficits, we propose a comprehensive clinical approach, as summarised in Fig. 1.

\section{Enteral nutrition support in ICU patients}

For the purpose of this commentary, we use the term "critically ill" to designate patients receiving mechanical ventilation for at least $48 \mathrm{~h}$. Patients requiring prolonged mechanical ventilation generally suffer from acute severe illness (SAPS III score $>40 ; \geq 10 \%$ expected mortality) and are expected to have a prolonged ICU stay. Our discussion will not refer to patients routinely managed in ICUs for a short time, such as post-operative cardiovascular patients.

In patients with an intact and functional gastrointestinal tract, when oral feeding is impossible, enteral feeding is thought to be more physiological than TPN and is also cheaper [16]. It is also accepted that EN may maintain intestinal integrity, immune and gut-barrier functions. Several studies have demonstrated consistent benefit of EN in decreasing septic morbidity, hospital and ICU length of stay, and mortality $[17,18]$. Moreover, the timing of initiation of EN is also important, as indicated by a retrospective cohort study conducted in a medical ICU that found greater mortality with delayed than with early EN [19].

The ESICM Working Group on Nutrition and Metabolism proposed relevant indications and contraindications as well as a pragmatic approach for prescribing EN [20]. These principles are summarised in Table 1. In their recommendations, early EN is proposed within 3 days of injury. However, achieving targeted nutritional goals with EN is often difficult, at least during the early phase after ICU admission [11-14]. Several studies reported failure to deliver adequate energy intake in clinical practice if only EN is used [14, 21-24]. The inability to deliver adequate energy intake, resulting in energy deficit, has been associated with increased morbidity and mortality in ICU patients $[8,25]$.

The implementation of feeding protocols has been proposed as a strategy to successfully deliver adequate nutritional support [26-28]. The ACCEPT study, a Canadian study conducted in 14 hospitals [29], showed that survival from intensive care was improved when evidence-based guidelines for nutrition were followed and larger amounts of nutrition were delivered more consistently. Other recent studies have shown that despite implementation of feeding protocols, nutritional requirements in the critically ill remain difficult to meet. Genton et al. studied 494 patients with a daily target caloric prescription of $20-25 \mathrm{kcal} / \mathrm{kg}$ (women) and $25-30 \mathrm{kcal} / \mathrm{kg}$ (men) of admission body weight [12]. On day 5 , less than $30 \%$ of the patients received $\geq 90 \%$ of the prescribed calories and their protein delivery reached only about $70 \%$ of requirements-clearly an under-nutrition situation. Another study showed that only $14 \%$ of ICU patients achieved $90 \%$ of prescribed 
Table 1 Indications, contraindications, and timing of enteral nutrition $(E N)$ in critically ill patients

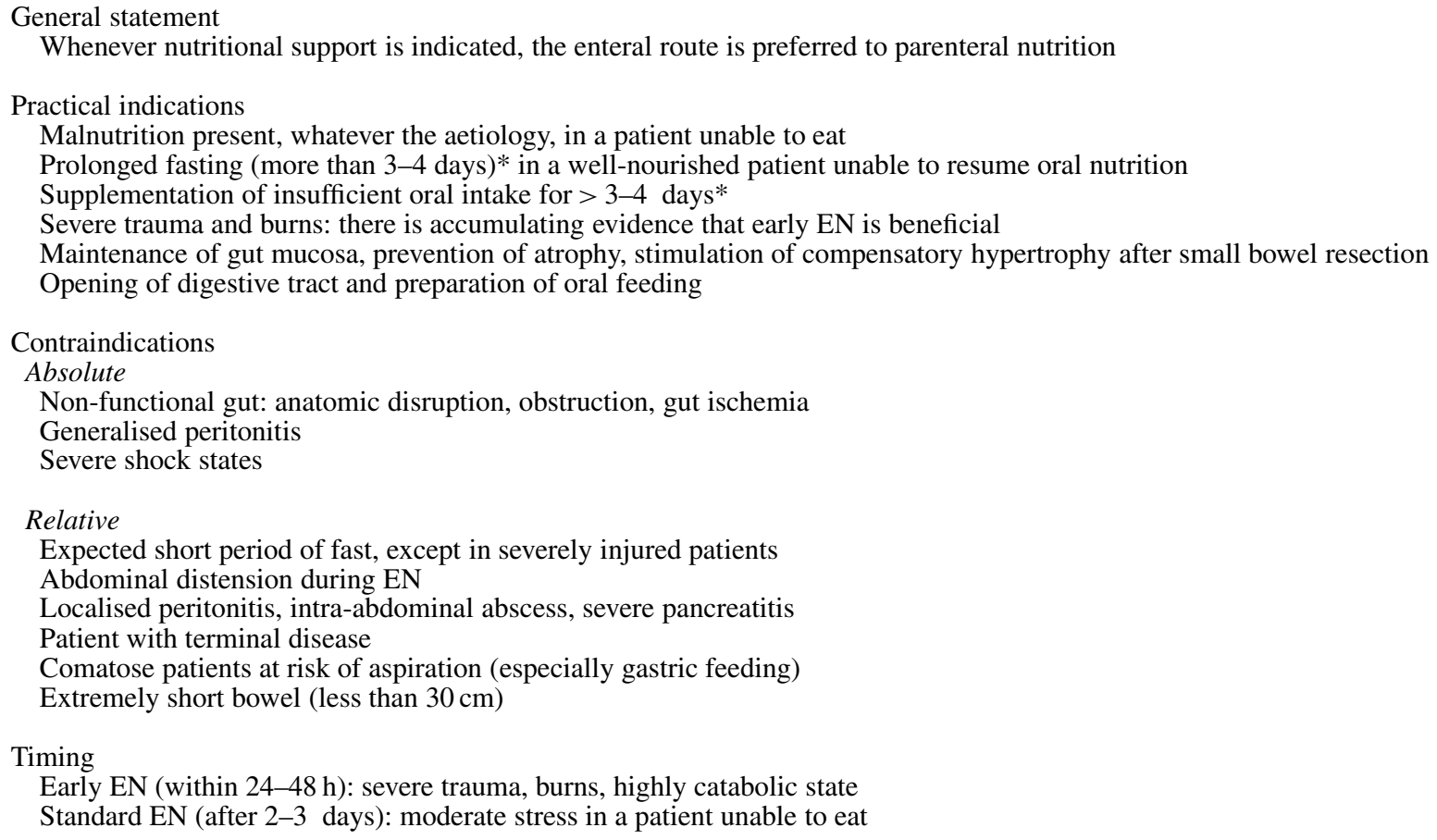

Adapted from reference [20], Table 3, p. 855, with kind permission of Springer Science and Business Media

* Evidence-based elements demonstrate clinical efficacy after delay as long as 7 days. However, clinical practice and experimental evidence strongly suggest that earlier onset of administration is warranted

calories within 3 days, based on a $25-35 \mathrm{kcal} / \mathrm{kg} /$ day need [13]. Spain etal. [30] also analysed the effect of implementing a nutritional support protocol. They demonstrated that only $58 \%$ of ICU patients included in an enteral feeding protocol achieved their targets. It is worth mentioning that when good compliance to the enteral feeding protocol was maintained over $80 \%$ of the prescribed volume was administered by day 3 .

\section{How can we achieve the target values of nutritional needs?}

Generally speaking, under- as well as over-feeding should be avoided [31, 32]. Various complications of overfeeding have been reported in several studies: hyperglycaemia, hyperlipidaemia, hepatic dysfunction, ventilation weaning difficulties [33-36]. However, the critically ill patient is more often at risk of hypocaloric than hypercaloric feeding. A recent study including medical ICU patients showed that hypocaloric feeding is associated with increased risk of bloodstream infection [37]. Another investigation demonstrated a reduction in the duration of mechanical ventilation associated with improved nutritional support [38]. A prospective study on the nutritional support in 48 critically ill patients staying $\geq 5$ days in the surgical ICU revealed that despite following a nutrition protocol, negative energy balance was very common during critical illness, with the lowest energy delivery during the first week, creating an important cumulative energy debt $(5,000-9,000 \mathrm{kcal})$ [8]. Additionally, there was an association between the cumulated energy deficit and the number of complications (infection rate, impaired wound healing), and the deficit was not compensated during the ICU stay. Another study by Dvir et al. also found a correlation between negative energy balance and complications in ICU patients [25].

Given the various patient presentations and conditions determined by the underlying nutritional status, extent of stress response, diagnosis, and severity of illness, different increasingly aggressive options of nutrition support can be considered, including: (1) allowing hypocaloric EN; (2) EN with slow augmentation until achievement of target delivery; (3) EN supplemented by PN by day 3 of attempts at maximisation of EN delivery; (4) early combination of EN plus PN started at admission. With the first two options, there would be a high risk of underfeeding in most critically ill patients. With a combined approach of EN plus PN initiated by day 3 of ICU admission, if the daily caloric goal is not achieved, most ICU patients would be fed adequately without accruing a large caloric debt. Although even more aggressive approaches are possible, 
Ibrahim et al. [39] showed that a too rapid initiation of nutrition therapy is associated with a poorer outcome. It is, however, important to note that in this study, using bolus feeds, even the early-feeding group received less than $28 \%$ of the estimated caloric and protein requirements. In our opinion, the conclusions of this study cannot be generalised. Therefore, it seems that the available evidence, along with financial considerations, would presently support an approach of initiating supplemental nutrition support by day 3 of attempts at maximisation of EN delivery.

\section{Enteral versus parenteral nutrition}

Until recently, early PN was not believed to be beneficial, due to its metabolic and infectious complications, more frequently observed during the early post-injury phase. There has been also reluctance to use PN because of concerns regarding complications related to hyperglycaemia, hypertriglyceridaemia, and gut mucosal atrophy [40, 41]. In a meta-analysis comparing EN to EN supplemented with PN, Dhaliwal et al. [42] recommended against starting $\mathrm{PN}$ at the same time as EN, arguing the absence of data suggesting a benefit from using EN and PN combined, and potential harm from PN in critically ill patients. However, it is important to note that (1) the study population was heterogeneous, with two of the five studies included investigating patients with burns; (2) all of the five studies included were conducted before 1998, at a time when the benefits of tight glycaemic control had not been shown; and (3) overfeeding was also commonly practised, frequently resulting in TPN-induced hyperglycaemia. This last point could explain the difference in the risk of infection. The concept of nutritional support has evolved since then: the recently published ESPEN guidelines \#8 [43] state that patients who fail to reach the lower target for intake using EN should receive additional PN. In daily practice the initiation of PN is often delayed, and only if after 7-10 days the patient is still unable to receive at least $60 \%$ of the caloric and nitrogen requirements with enteral feeding is supplementary PN then indicated. However, this concept must be revisited. Indeed, Simpson et al. in a meta-analysis of 465 publications, compared the use of TPN versus EN [44]. The results, based on nine trials with complete follow-up, showed decreased mortality with the use of TPN [odds ratio (OR) of death $0.51,95 \%$ confidence interval (CI) $0.27-0.97, p=0.04]$ despite an increase of infectious complications in the TPN group (OR 1.66, 95\% CI 1.09-2.51, $p=0.02$ ). The benefit

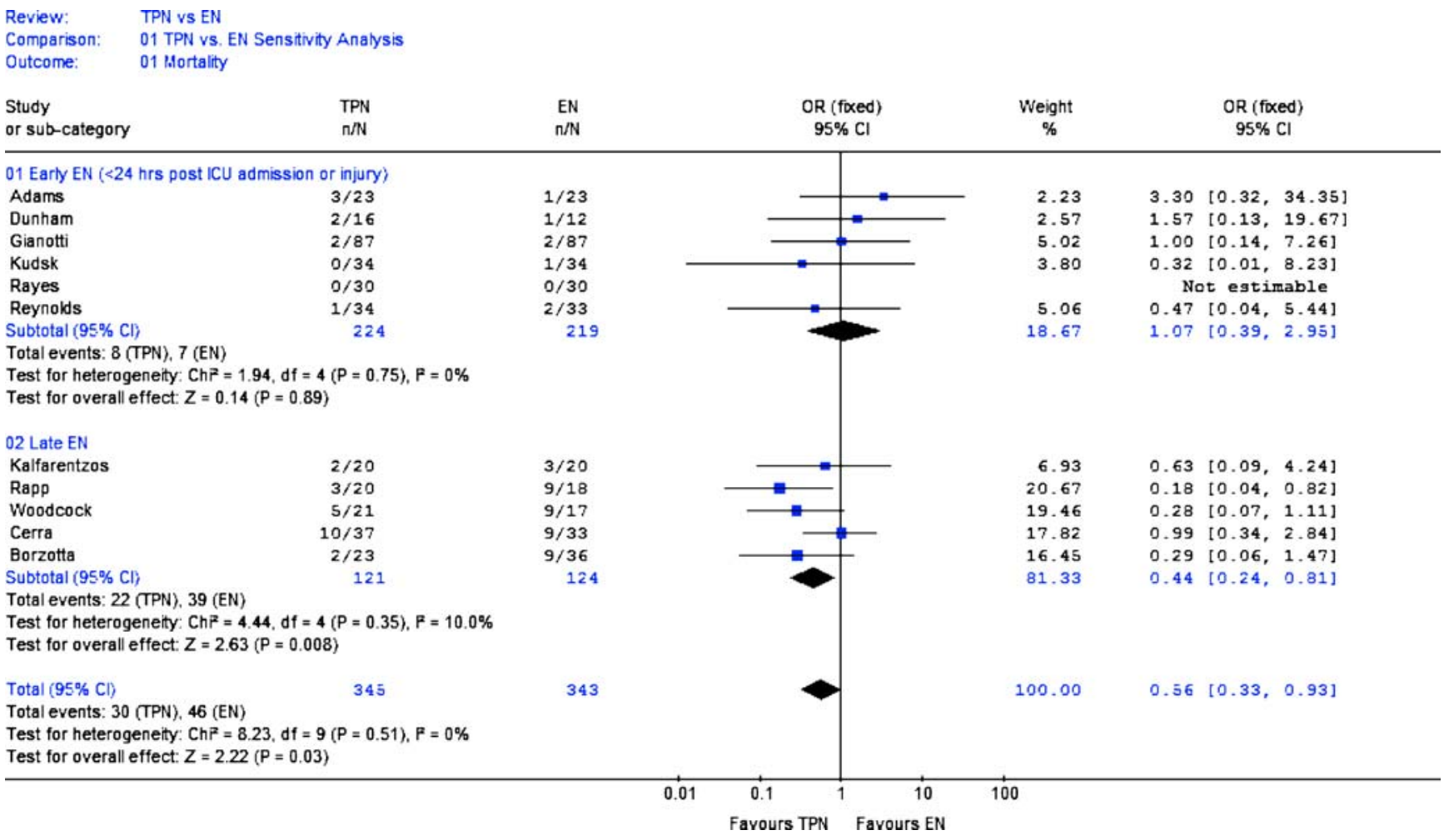

Fig. 2 Total parenteral nutrition $(T P N)$ versus enteral nutrition $(E N)$ : effect on mortality, sensitivity analysis and subgroup analysis. $O R$ Odds ratio; $N$ total number of patients in the group; $n$ number of patients who died in the group. Adapted from reference [44], Fig. 4, p. 19, with kind permission of Springer Science and Business Media 
was even more important when trials compared the use of early TPN with delayed EN ( $>24 \mathrm{~h}$ ), (OR $0.29,95 \%$ CI $0.12-0.70, p=0.006$ ) (Fig. 2). The authors recommended the administration of TPN in patients in whom EN could not be initiated within $24 \mathrm{~h}$ of ICU admission or injury, concluding that early TPN may be superior to delayed EN.

Another meta-analysis in critically ill patients is consistent with the finding that TPN is not associated with incremental mortality despite an increase of infection [45].

As an alternative to central administration of TPN, some advocate the use of peripheral PN (PPN), when a central line access is not available. PPN could be of benefit in ICU patients without the risks associated with venous central catheterisation [46-48]. Although PPN might be an effective alternative to central venous administration of TPN, the short-term tolerance of PPN might be limited to 5-7 days. More prospective documentation is needed before any conclusion can be reached regarding wider use of this modality in clinical practice.

Contemporary metabolic and nutritional issues: tight glycaemic control is mandatory!

Recognising the presence of altered and increased metabolic requirements is central to understanding why nutrition is so important for ICU patients. It is likely that some of the side effects related to TPN observed in studies over the past decade were due to inadequate glycaemic control. Indeed, trauma and/or septic ICU patients have increased substrate turnover of carbohydrates, lipids and amino acids and altered end-organ perfusion combined with peripheral insulin resistance, all processes linked to systemic inflammation. The increased demand for glucose and amino acids derives from protein breakdown, and the huge increase in skeletal muscle catabolism is the most evident consequence. Optimising the particularly increased substrate requirements and overcoming insulin resistance is considered central to positively affect clinical outcomes. Since the landmark Leuven study, tight glycaemic control with the use of insulin is considered central to improving morbidity and mortality in critically ill patients [49]. The survival benefits of intensive insulin therapy seem to depend mainly on the maintenance of normoglycaemia rather than glycaemia-independent insulin effects [50]. New preliminary evidence, however, questions tight glycaemic control due to a possible increase in hypoglycaemia (Preiser JC, Tight glycemic control in real life: results of the Glucontrol Study, presented at the 19th Annual ESICM meeting, Barcelona, Spain, 24-27 September 2006) [51]. As hypoglycaemia has been associated with increased mortality, the need for adequate energy intake may be crucial to obtain the beneficial effects of tight glycaemic control. Van den Berghe et al. reported an incidence of hypoglycaemia of about 19\% without increased morbidity or mortality, but the patients in that study were aggressively fed enterally and parenterally from the time of ICU admission [52].

As the majority of the parenteral feeding trials were accomplished before the era of tight glucose control, it seems likely that their unfavourable outcomes were due to hyperglycaemia and not exclusively to TPN.

\section{A revision of the dogma is needed: We should apply EN with supplementary PN when EN alone fails to reach the nutrition goal}

As we have seen, and contrary to former beliefs, recent meta-analyses show that TPN does not involve excess mortality [44, 45]. These reports convey a concept that is a major breakthrough in current routine nutritional support in ICU patients by promoting a much wider use of PN. Current evidence suggests that enteral feeding is the preferred route. Unfortunately, underfeeding due to insufficient delivery is repeatedly reported and is related to an increased risk of developing or aggravating an existing malnutrition state and associated with increased morbidity $[8,53]$. This can be prevented by proper nutrition protocols that include timely and adequate enteral feeding. When EN delivery is inadequate, PN supplementation usually allows immediate $100 \%$ coverage of these needs. We propose that if EN fails to meet the patient's nutritional needs within 3 days, immediate PN must be initiated to achieve $100 \%$ of energy and protein targets by day 4. A sequential approach should be considered, with de-escalation of PN as EN is approaching the goals. Simultaneously, glycaemic control, avoiding hypoglycaemia by appropriate nutritional support along with insulin administration, is necessary [49]. By implementing such protocols, improved matching between energy requirements and delivery can be achieved. Combined nutritional support will also allow the protein needs to be met sooner during critical illness. A randomised controlled trial is warranted to confirm the outcome benefits of the proposed approach. 


\section{References}

1. Berard MP, Zazzo JF, Condat P, Vasson MP, Cynober L (2000) Total parenteral nutrition enriched with arginine and glutamate generates glutamine and limits protein catabolism in surgical patients hospitalized in intensive care units. Crit Care Med 28:3637-3644

2. Monk DN, Plank LD, Franch-Arcas G, Finn PJ, Streat SJ, Hill GL (1996) Sequential changes in the metabolic response in critically injured patients during the first 25 days after blunt trauma. Ann Surg 223:395-405

3. Isenring EA, Capra S, Bauer JD (2004) Nutrition intervention is beneficial in oncology outpatients receiving radiotherapy to the gastrointestinal or head and neck area. Br J Cancer 91:447-452

4. Kyle UG, Genton L, Heidegger CP, Karsegard VL, Maisonneuve N, Huber O, Pichard C (2006) Hospitalized mechanically ventilated patients are at higher risk of enteral underfeeding than non-ventilated patients. Clin Nutr 25:727-735

5. Dempsey DT, Mullen JL, Buzby GP (1988) The link between nutritional status and clinical outcome: can nutritional intervention modify it? Am J Clin Nutr 47:352-356

6. Daley J, Khuri SF, Henderson W, Hur K, Gibbs JO, Barbour G, Demakis J, Irvin G 3rd, Stremple JF, Grover F, McDonald G, Passaro E Jr., Fabri PJ, Spencer J, Hammermeister K, Aust JB, Oprian C (1997) Risk adjustment of the postoperative morbidity rate for the comparative assessment of the quality of surgical care: results of the National Veterans Affairs Surgical Risk Study. J Am Coll Surg 185:328-340

7. Giner M, Laviano A, Meguid MM, Gleason JR (1996) In 1995 a correlation between malnutrition and poor outcome in critically ill patients still exists. Nutrition 12:23-29

8. Villet S, Chiolero RL, Bollmann MD, Revelly JP, Cayeux RNM, Delarue J, Berger MM (2005) Negative impact of hypocaloric feeding and energy balance on clinical outcome in ICU patients. Clin Nutr 24:502-509

9. Kyle UG, Genton L, Pichard C (2005) Hospital length of stay and nutritional status. Curr Opin Clin Nutr Metab Care 8:397-402

10. Berger MM, Chiolero RL, Pannatier A, Cayeux MC, Tappy L (1997) A 10year survey of nutritional support in a surgical ICU: 1986-1995. Nutrition 13:870-877

11. Heyland D, Cook DJ, Winder B, Brylowski L, van deMark H, Guyatt G (1995) Enteral nutrition in the critically ill patient: a prospective survey. Crit Care Med 23:1055-1060
12. Genton L, Dupertuis YM, Romand JA, Simonet ML, Jolliet P, Huber O, Kudsk KA, Pichard C (2004) Higher calorie prescription improves nutrient delivery during the first 5 days of enteral nutrition. Clin Nutr 23:307-315

13. McClave SA, Sexton LK, Spain DA, Adams JL, Owens NA, Sullins MB, Blandford BS, Snider HL (1999) Enteral tube feeding in the intensive care unit: factors impeding adequate delivery. Crit Care Med 27:1252-1256

14. Adam S, Batson S (1997) A study of problems associated with the delivery of enteral feed in critically ill patients in five ICUs in the UK. Intensive Care Med 23:261-266

15. Bauer P, Charpentier C, Bouchet C, Nace L, Raffy F, Gaconnet N (2000) Parenteral with enteral nutrition in the critically ill. Intensive Care Med 26:893-900

16. Gramlich L, Kichian K, Pinilla J, Rodych NJ, Dhaliwal R, Heyland DK (2004) Does enteral nutrition compared to parenteral nutrition result in better outcomes in critically ill adult patients? A systematic review of the literature. Nutrition 20:843-848

17. Zaloga GP (1999) Early enteral nutritional support improves outcome: hypothesis or fact? Crit Care Med 27:259-261

18. Marik PE, Zaloga GP (2001) Early enteral nutrition in acutely ill patients: a systematic review. Crit Care Med 29:2264-2270

19. Artinian V, Krayem H, DiGiovine B (2006) Effects of early enteral feeding on the outcome of critically ill mechanically ventilated medical patients. Chest 129:960-967

20. Jolliet P, Pichard C, Biolo G, Chiolero R, Grimble G, Leverve X, Nitenberg G, Novak I, Planas M, Preiser JC, Roth E, Schols AM, Wernerman J (1998) Enteral nutrition in intensive care patients: a practical approach. Working Group on Nutrition and Metabolism, ESICM. European Society of Intensive Care Medicine. Intensive Care Med 24:848-859

21. Woodcock NP, Zeigler D, Palmer MD, Buckley P, Mitchell CJ, MacFie J (2001) Enteral versus parenteral nutrition: a pragmatic study. Nutrition 17:1-12

22. Reid CL, Campbell IT, Little RA (2004) Muscle wasting and energy balance in critical illness. Clin Nutr 23:273-280

23. Weissman C, Kemper M, Askanazi J, Hyman AI, Kinney JM (1986) Resting metabolic rate of the critically ill patient: measured versus predicted. Anesthesiology 64:673-679
24. De Jonghe B, Appere-De-Vechi C, Fournier M, Tran B, Merrer J, Melchior JC, Outin H (2001) A prospective survey of nutritional support practices in intensive care unit patients: What is prescribed? What is delivered? Crit Care Med 29:8-12

25. Dvir D, Cohen J, Singer P (2006) Computerized energy balance and complications in critically ill patients: an observational study. Clin Nutr 25:37-44

26. Mackenzie SL, Zygun DA, Whitmore BL, Doig CJ, Hameed SM (2005) Implementation of a nutrition support protocol increases the proportion of mechanically ventilated patients reaching enteral nutrition targets in the adult intensive care unit. JPEN J Parenter Enteral Nutr 29:74-80

27. Williams TA, Leslie GD (2005) A review of the nursing care of enteral feeding tubes in critically ill adults: part II. Intensive Crit Care Nurs 21:5-15

28. Heyland DK, Dhaliwal R, Day A, Jain M, Drover J (2004) Validation of the Canadian clinical practice guidelines for nutrition support in mechanically ventilated, critically ill adult patients: results of a prospective observational study. Crit Care Med 32:2260-2266

29. Martin CM, Doig GS, Heyland DK, Morrison T, Sibbald WJ (2004) Multicentre, cluster-randomized clinical trial of algorithms for critical-care enteral and parenteral therapy (ACCEPT). CMAJ 170:197-204

30. Spain DA, McClave SA, Sexton LK, Adams JL, Blanford BS, Sullins ME, Owens NA, Snider HL (1999) Infusion protocol improves delivery of enteral tube feeding in the critical care unit. JPEN J Parenter Enteral Nutr 23:288-292

31. Radrizzani D, Iapichino G (1998) Nutrition and lung function in the critically ill patient. Clin Nutr 17:7-10

32. Krishnan JA, Parce PB, Martinez A, Diette GB, Brower RG (2003) Caloric intake in medical ICU patients: consistency of care with guidelines and relationship to clinical outcomes. Chest 124:297-305

33. Takiguchi SA (1990) Report of a hidden case of overfeeding. Heart Lung 19:639-640

34. Klein CJ, Stanek GS, Wiles CE 3rd (1998) Overfeeding macronutrients to critically ill adults: metabolic complications. J Am Diet Assoc 98:795-806

35. Van den Berg B, Stam H (1988) Metabolic and respiratory effects of enteral nutrition in patients during mechanical ventilation. Intensive Care Med 14:206-211 
36. Lo HC, Lin CH, Tsai LJ (2005) Effects of hypercaloric feeding on nutrition status and carbon dioxide production in patients with long-term mechanical ventilation. JPEN J Parenter Enteral Nutr 29:380-387

37. Rubinson L, Diette GB, Song X, Brower RG, Krishnan JA (2004) Low caloric intake is associated with nosocomial bloodstream infections in patients in the medical intensive care unit. Crit Care Med 32:350-357

38. Barr J, Hecht M, Flavin KE, Khorana A, Gould MK (2004) Outcomes in critically ill patients before and after the implementation of an evidence-based nutritional management protocol. Chest 125:1446-1457

39. Ibrahim EH, Mehringer L, Prentice D, Sherman G, Schaiff R, Fraser V, Kollef MH (2002) Early versus late enteral feeding of mechanically ventilated patients: results of a clinical trial. JPEN J Parenter Enteral Nutr 26:174-181

40. Hill SA, Nielsen MS, Lennard-Jones JE (1995) Nutritional support in intensive care units in England and Wales: a survey. Eur J Clin Nutr 49:371-378

41. Kudsk KA, Croce MA, Fabian TC, Minard G, Tolley EA, Poret HA, Kuhl MR, Brown RO (1992) Enteral versus parenteral feeding. Effects on septic morbidity after blunt and penetrating abdominal trauma. Ann Surg 215:503-511; discussion 511-503

42. Dhaliwal R, Jurewitsch B, Harrietha D, Heyland DK (2004) Combination enteral and parenteral nutrition in critically ill patients: harmful or beneficial? A systematic review of the evidence. Intensive Care Med 30:1666-1671
43. Kreymann KG, Berger MM, Deutz NE, Hiesmayr M, Jolliet P, Kazandjiev G, Nitenberg G, van den Berghe G, Wernerman J, Ebner C, Hartl W, Heymann C, Spies C (2006) ESPEN Guidelines on Enteral Nutrition: intensive care. Clin Nutr 25:210-223

44. Simpson F, Doig GS (2005) Parenteral vs. enteral nutrition in the critically ill patient: a meta-analysis of trials using the intention to treat principle. Intensive Care Med 31:12-23

45. Heyland DK, Dhaliwal R, Drover JW, Gramlich L, Dodek P (2003) Canadian clinical practice guidelines for nutrition support in mechanically ventilated, critically ill adult patients. JPEN J Parenter Enteral Nutr 27:355-373

46. Anderson $\mathrm{AD}, \mathrm{McNaught} \mathrm{CE}$, MacFie J, Tring I, Barker P, Mitchell CJ (2003) Randomized clinical trial of multimodal optimization and standard perioperative surgical care. Br J Surg 90:1497-1504

47. Culebras JM, Martin-Pena G, Garciade-Lorenzo A, Zarazaga A, RodriguezMontes JA (2004) Practical aspects of peripheral parenteral nutrition. Curr Opin Clin Nutr Metab Care 7:303-307

48. Thomas DR, Zdrodowski CD, Wilson MM, Conright KC, Diebold M, Morley JE (2005) A prospective, randomized clinical study of adjunctive peripheral parenteral nutrition in adult subacute care patients. J Nutr Health Aging 9:321-325
49. Van den Berghe G, Wouters P, Weekers F, Verwaest $C$, Bruyninckx F, Schetz M, Vlasselaers D, Ferdinande P, Lauwers P, Bouillon R (2001) Intensive insulin therapy in the critically ill patients. N Engl J Med 345:1359-1367

50. Ellger B, Debaveye Y, Vanhorebeek I, Langouche L, Giulietti A, van Etten E, Herijgers P, Mathieu C, van den Berghe G (2006) Survival benefits of intensive insulin therapy in critical illness: impact of maintaining normoglycemia versus glycemia-independent actions of insulin. Diabetes 55:1096-1105

51. Brunkhorst FM, Kuhnt E, Engel C (2005) Intensive insulin therapy in patients with severe sepsis and septic shock is associated with an increased rate of hypoglycemia: results from a randomized multicenter study (VISEP). Infection 33:19-20

52. Van den Berghe G, Wilmer A, Hermans G, Meersseman W, Wouters PJ, Milants I, van Wijngaerden E, Bobbaers H, Bouillon R (2006) Intensive insulin therapy in the medical ICU. N Engl J Med 354:449-461

53. McWhirter JP, Pennington CR (1994) Incidence and recognition of malnutrition in hospital. BMJ 308:945-948

54. Jolliet P, Pichard C, Biolo G, Chiolero R, Grimble G, Leverve X, Nitenberg G, Novak I, Planas M, Preiser JC, Roth E, Schols AM, Wernerman J (1999) Enteral nutrition in intensive care patients: a practical approach. Clin Nutr 18:47-56 